Authors' opinion

\title{
Interdisciplinary analysis of palliative care institutionalization trends in Russia
}

\author{
Irina L. Krom ${ }^{1,2}$, Marina V. Erugina ${ }^{1}$, Elena A. Andriyanova ${ }^{1}$, Dmitrii A. Timofeev ${ }^{1}$, Alexander B. Shmerkevich ${ }^{1}$ \\ ${ }^{1}$ Saratov State Medical University n.a. V.I. Razumovsky, Saratov, Russia \\ ${ }^{2}$ Centre of Medical-and-Sociological Research, Saratov, Russia
}

Received 14 October 2016, Revised 21 February 2017, Accepted 30 March 2017

(C) 2016, Krom I.L., Erugina M.V., Andriyanova E.A., Timofeev D.A., Shmerkevich A.B.

(C) 2016, Russian Open Medical Journal

\begin{abstract}
Beginning with the XX century health care is considered to be the largest social institution with the delegated strategic objectives. In the authors' opinion, four subinstitutions can be distinguished in the social Institute of Health Care, according to the functions they perform: "Primary health care", "Ambulance", "Specialized medical care", "Palliative medical care". The analysis of trends of the institutionalization of subinstitute "Palliative medical care" is presented by the authors in the methodological plane of the system of social and structural functions, proposed by T. Parsons. In the adopted legislative documents in Russia, palliative care is considered as a palliative medical care, which determined the nature and content of palliative care to patients with chronic diseases. The medicalization of palliative care is discussed by the authors from the perspective of the dysfunctional practices of a forming in Russia subinstitute of palliative care.
\end{abstract}

Keywords: institute of public health, AGIL system, subinstitution, palliative medical care

Cite as Krom IL, Erugina MV, Andriyanova EA, Timofeev DA, Shmerkevich AB. Interdisciplinary analysis of palliative care institutionalization trends in Russia. Russian Open Medical Journal 2017; 6: e0207.

Correspondence to Irina L. Krom. Phone: + 7917209 4802. E-mail: Irina.crom@yandex.ru.

Public health structure is changing due to ongoing demographic changes in the modern world, where the main trend is the aging of the population. The majority of people towards the end of life are in pain from progressive diseases: cardiovascular, cancer and others in recent decades, especially in the western industrialized countries [1]. The number of cancer patients who need palliative care in the subsequent years will increase. This is due to the fact that we expect the increasing of cancer patients' number due to early diagnosis, expansion of treatment options and increased life expectancy after a specific treatment [2].

Because of the advances in modern medicine patients have the opportunity to live longer with chronic diseases that limit their ability to live, suffer, and as a result they will need palliative care [2]. In modern context right after diagnosis was made or in case of debilitating diseases, palliative care is indicated for all patients of any age and regardless of the diagnosis [3]. In recent years the process of palliative care institutionalization is taking place in Russia [3]. The aim of palliative care is in improving patients and their families quality of life when they are facing a life-threatening disease $[4,5]$.

Russian Federal Law No. 323-FZ dated November 21, 2011 (title: "On the basis of public health protection in the Russian Federation") [6] regulates rendering of assistance of the palliative care in Russia. The law defines palliative care as a complex of medical interventions aimed at getting rid of the pain and facilitate other severe manifestations of the disease, in order to improve the quality of life of terminally ill people, also the law regulates palliative care provision carried out by health care workers trained in rendering palliative care in outpatient and inpatient settings.
The provision of medical care depending on aspects, conditions and forms of its provision by medical institutions is regulated by Federal Law No. 323-FZ [7]. Before the abovementioned Law was adopted palliative care in Russia was not regarded as an independent type of medical care, but it was rendered to the population in case of certain diseases and under some conditions.

Procedure of palliative care rendering to adult population was approved by the Order No. 1343n of the Russian Ministry of Health dated December 21, 2012 [8]. The analysis of this document reveals rather serious problems in normative regulation of palliative care rendering.

The following main problems should be mentioned: there is no list of health status that allow to render this type of medical care; there are no clear criteria to consider a patient among the group of terminally ill; there are no indications for hospitalization of patients who need around the clock medical supervision, treatment and care in a of palliative care department. ". Besides, such organizations as "Hospice", "Nursing home" are not among the organizations which render palliative care to adult population. There is no normative basis for the rendering palliative care to children. The abovementioned circumstances limit the availability of palliative care to the population [9].

Taking into consideration the experience of Russian and foreign research data in accordance with the Order of 2012 [8], in 2015 , there have been some significant changes in the normative basis of palliative care rendering in Russia. A new order of Ministry of Health of Russia No. 187n "On the approval of the order of 
rendering palliative care to adult population" came into force on the May 23, 2015. The eponymous order No.1343n dated December 21, 2012 is declared null and void. The shortcomings of the previous edition are eliminated in the new order [10]. The main goal of palliative care which has not been formulated in the previous order generally is clearly identified in the new one. The main goal of palliative care is in effective and timely relief from pain and relief of other serious manifestations of the disease in order to improve the quality of life of terminally ill persons until their death. All the above mentioned means that for the ensuring of palliative care availability, scientific and methodological basis and development of a unified classification of status under which palliative care is needed and should be organized is required. It is obvious that medical care rendering orders should be complemented by this classification.

The formation of palliative care subinstitute in Russia is subject to the general institutionalization logic, which consists of several successive stages [11]:

i) the emergence of needs that require a joint organized actions;

ii) formation of common goals;

iii) the emergence of social norms and rules in the course of spontaneous social interaction, carried out by trial and error method;

iv) the appearance of the procedures related to rules and regulations;

v) institutionalization of rules and regulations, procedures, i.e. their adoption, practical application;

vi) the establishment a system of sanctions for the maintenance of norms and rules, differentiation of their application in individual cases;

vii) creation statuses and roles system, comprising all the members of subinstitute.

The palliative care institutionalization trends analysis in modern Russia is presented in the methodological perspective of social and structural functions system (named as AGIL), proposed by T. Parsons. Fennell et al. note that this and other modern theories can be useful for the study of health institutionalization trends [12].

\section{Adaptation}

Roles are impersonal, the distribution of roles in the palliative care system associated with the performance of certain functions. Patient with chronic disease is a palliative care user. Medical organizations, health management licensing authorities, patients, doctors, and medical care quality control experts interact in the process of health care organization. The aim of medical and organizational process participants' interaction is to submitting quality palliative care to the patient.

The existing in many economically developed countries modern system of palliative care assumes the optimal resources allocation among radical treatment and palliative care, and reflects the actual needs of patients with chronic diseases [13]. An individual choice of a patient when he is planning a palliative care is a key moment when the service is provided [14].

\section{Goal setting}

The society implements education of specialists that presuppose the professionalization of fulfilling them their functions. In the opinion of D. Nevzorova [15], who is the Ministry of Health of Russia chief supernumerary specialist in palliative care, for the forming the system of palliative care in Russia it is necessary to train specialists fundamentals of palliative care: communication, features of terminal states going, aspects of the participants activity coordination of medical and organizational process. Under modern trends to the interaction of participants of anesthesia, to the usage of narcotic drugs and psychotropic substances, to the legal basis provision of palliative care.

\section{Integration}

In the context of the integrative function rendering and monitoring the quality of medical care processes are formed on the basis of fulfilling medical care standards (protocols). Optimization of medical organizations activity, insurance companies, state supervisory authority and medical staff is aimed at ensuring the continuous improvement of medical care quality to the population [16].

Palliative care institutionalization in modern Russia assumes the integration and interaction of the system entities:

i) the most independent form of integration is the coordination of joint work;

ii) mutual complement of various organizations and agencies activity - is cooperation;

iii) integration - the association of organizations and departments.

Models of interaction can be considered in relation to management structures, work planning, financing, organization of professional and other activities [17].

Modern advanced practice of palliative care is based on the principle of an interdisciplinary approach to rendering medical care to patients with chronic diseases. Such kind of principle presupposes together with comprehensive special treatment to render patients and their families different types of social and psychological support.

Latent function (maintenance of a valuable sample)

Social control is a mechanism of self-regulation in social systems (groups, collectives, organizations and society as a whole), performing it with the help of normative regulation of people's behavior [18]. Latent function defines balanced development, predictability, stability of social relations functioning. Social control provides an efficient behavior of participants of health care rendering process.

In the context of social control under palliative help institutionalization we consider social responsiveness of subinstitute, which mainly evaluate non-clinical settings of medical care rendering from the viewpoint of realization of universal patient expectations [19].

In a period of intense social transformations in the society, there are occasions when the changing social needs are not adequately reflected in the structure and function of existing social institutions [20]. Such kind of discrepancy can lead to a dysfunction. Conceptualization of dysfunctions is associated with works of Robert Merton. "To explore the dysfunctional aspects of social activity means to analyze those aspects of social life, which are a challenge to the existing order of things" [21]. 
Organization of medical palliative care in Russia takes place simultaneously with the improvement of legal acts, which significantly slows down the process of palliative care institutionalization to the population and predetermines the limit of its availability. Until now, indicators of health system responsiveness are not considered in the rendering of palliative care in Russia.

In the adopted legislative documents in Russia palliative care is considered as a palliative medical care $[22,23]$, which identified the nature and content of palliative care to patients with chronic diseases. In the process of formation of the normative base the principle of an integrative approach to the organization of palliative care was not reflected. A medicalisation of palliative care is taking place, which is discussed in the literature as well as a medicalization of death [24]. We consider both in the context of the dysfunctional practices of subinstitute of palliative care.

Thus, at present time the need of a scientific understanding of the interdisciplinary medical and sociological context of palliative care phenomenon is evident. As the methodological basis of the implementation of the mentioned context we can accept a multiprofessional and a multidisciplinary approach, which help to avoid the dysfunctional practices of a forming in Russia palliative care subinstitute. Public health status in modern Russia, the increased morbidity and disability of the population with chronic diseases in all age groups suggests the need to overcome the medicalization in forming the policies of palliative care to patients with chronic diseases in modern Russia.

\section{Conflict of interest: none declared.}

\section{References}

1. Murtagh FEM, Preston M, Higginson I. Patterns of dying: palliative care for non-malignant disease. Clin Med 2004; 4: 39-44. https://doi.org/10.7861/clinmedicine.4-1-39.

2. Ireland National Advisory Committee. Report of the National Advisory Committee on Palliative Care. Department of Health and Children, Ireland, 2001; $157 \mathrm{p}$.

3. National Consensus Project for Quality Palliative Care. Clinical Practice Guidelines for quality palliative care, executive summary. J Palliat Med 2004; 7(5): 611-627. https://doi.org/10.1089/ipm.2004.7.611.

4. Better Palliative Care for Older People. E. Davis and IJ. Higginson, eds. Geneva: World Health Organization, 2004; 40 p.

5. Recommendation Rec (2003) 24 of the Committee of Ministers to member states on the organization of palliative care. Council of Europe, 2003; $81 \mathrm{p}$.

6. On approval of the provision of palliative care to children with mental and behavioral disorders: Order of Ministry of Health No. 566n of the Russian Federation dated May 17, 2012. Russian. http://ivo.garant.ru/\#/document/70200618/paragraph/1:1.

7. On the bases of the protection of health of citizens in the Russian Federation: the Federal Law No. 323-FZ dated November 21, 2011. Russian. http://ivo.garant.ru/\#/document/12191967/paragraph/1:2.

8. On approval of the provision of palliative care to adults: Order No. $1343 n$ of Ministry of Health of the Russian Federation dated December 21, $2012 . \quad$ Russian http://www.garant.ru/products/ipo/prime/doc/70217572.

9. Erugina MV. Regulatory-legal support of palliative medical care. How to help terminally ill patients? The problem of availability of palliative care. Law Issues in Health Care 2014; (11): 40-47. Russian

10. On approval of the provision of palliative care to adults: Order No. 287n of Ministry of Health of the Russian Federation dated April 14, 2015. http://www.garant.ru/products/ipo/prime/doc/70914388.
11. Frolov SS. Sociology. Moscow, Russia: Publishing Corporation "Logos", 1996: 173-175. Russian

12. Fennell ML, Adams CM. U.S. health-care organizations: complexity, turbulence, and multilevel change. Annual Review of Sociology 2011; 37: 205-219. https://doi.org/10.1146/annurev.soc.012809.102612.

13. Solovyev VI, Kulikov EP. The role and place of the organizational form of palliative treatment of patients with malignant tumors in the structure of regional health care. Rossiyskij Mediko-Biologicheskij Vestnik imeni Akademika I.P. Pavlova 2004; (1-2): 54-62. Russian

14. Borgstrom E. Planning for an (un)certain future: choice within English end-of-life care. Current Sociology 2015); 63(5): 700-713. https://doi.org/10.1177/0011392115590084.

15. Nevzorova D. Problems are first of all in the minds of medical professionals. Medical Bulletin 2015; 22: 13. Russian

16. Yerugina MV. Scientific substantiation of the concept of optimization of the quality of medical care within the interaction of participants of medical and organizational process: DSc dissertation. Ryazan, Russia, 2009. Russian

17. Kachmazova BA. Theory and practice of interaction of sociology of medicine and medico-social work: PhD dissertation. Volgograd, Russia, 2008. Russian

18. Slepenkov NM, Averin YuP. Fundamentals of social control theory. Moscow, Russia, 1990; 22 p. Russian

19. Shulgina SV. The responsiveness of the health care system and its characteristics. Problems of Social Hygiene, Health and History of Medicine 2015; 23(1): 25-27. Russian

20. Bode I. A 'world culture' of institutional ambiguity? Comparing the reorganization of hospital care in Germany and Mexico. Current $\begin{array}{lll}\text { Sociology } & \text { 2015; 63(3): } & \text { 411-431. }\end{array}$ https://doi.org/10.1177/0011392114527996.

21. Giddens E. Sociology. Moscow, Russia, 1999. Russian

22. Yerugina MV, Krom IL, Shmerkevich AB. Content analysis of legal acts and the determination of the directions of optimization of palliative care in modern Russia. Saratov Journal of Medical Scientific Research 2015; 11(4): 506-510. Russian

23. Krom IL, Yerugina MV, Shmerkevich AB. Modern palliative care strategy (review). Saratov Journal of Medical Scientific Research 2015; 11(4): 503-506. Russian

24. Vatovec Ch, Senier L, Bell M. The ecology of dying: commodity chains, governance, and the medicalization of end-of-life care. In: Ecological Health: Society, Ecology and Health (Advances in Medical Sociology, Volume 15). K.M. Gislason, ed. Emerald Group Publishing Limited, UK: 195-215.

\section{Authors:}

Irina L. Krom - MD, DSc, Professor, Department of Health Organization and Public Health with the Courses of Law and History of Medicine, Saratov State Medical University n.a. V.I. Razumovsky, Saratov, Russia; Centre of Medical-Sociological Research, Saratov, Russia. http://orcid.org/00000001-8728-3960

Marina V. Erugina - MD, DSc, Professor, Head of Department of Health Organization and Public Health with the Courses of Law and History of Medicine, Saratov State Medical University n.a. V.I. Razumovsky, Saratov, Russia. http://orcid.org/0000-0003-4253-5313.

Elena A. Andriyanova - DSc, Professor, Head of Department of Philosophy, Humanitarian Sciences and Psychology, Saratov State Medical University n.a. V.I. Razumovsky, Saratov, Russia. http://orcid.org/0000-0002-62508331.

Dmitrii A. Timofeev - MD, DSc, Professor, Department of Health Organization and Public Health with the Courses of Law and History of Medicine, Saratov State Medical University n.a. V.I. Razumovsky, Saratov, Russia. http://orcid.org/0000-0003-1994-4629.

Alexander B. Shmerkevich - MD, PhD, applicant of the Department of Health Organization and Public Health with the Courses of Law and History of Medicine, Saratov State Medical University n.a. V.I. Razumovsky, Saratov, Russia. http://orcid.org/0000-0002-3177-0767. 